\title{
THE MIDDLEBROOK-DUBOS HEMAGGLUTINATION TEST FOR TUBERCULOSIS IN CHILDREN AND ADULTS ${ }^{1}$
}

\author{
By ANTON JOSIUKAS, T. E. ROY, AND GLADYS BOYD \\ (From The Department of Pediatrics, University of Toronto, The Research Institute of The \\ Hospital for Sick Children, and The Department of Bacteriology, University of \\ Toronto, Toronto, Canada)
}

(Submitted for publication May 10, 1954; accepted June 23, 1954)

Middlebrook and Dubos (1) described a hemagglutination reaction designed to detect serum antibodies to certain components of $\mathbf{M}$. tuberculosis. Early reports suggested that this test might have valuable clinical applications both in the diagnosis of tuberculosis and in evaluating the activity of the disease (2-7). Subsequent reports on its clinical usefulness have been less encouraging (816). Many modifications of the test have been devised in an attempt to make it more specific. These have included more thorough absorption of sera with normal sheep erythrocytes to remove heterophile antibodies (17), the substitution of human Group O cells for sheep erythrocytes (1821), the use of fowl erythrocytes (22), and the use of collodion particles (23). Middlebrook (24) introduced a hemolytic modification which has received considerable study (25-33). A slide agglutination test has been used (34). Different products of the tubercle bacillus have been used $(1,5,15,20,23,29,33,35,36)$ in attempts to make the test more specific, and modifications of the method of adsorbing antigens on the erythrocytes have included the use of tannic acid (37-39), inulin or trypsin (38), and treatment of the cells with Forssman antibody (30). In an effort to explain false negative reactions, "incomplete" or "blocking" antibodies have been looked for by the use of such diluents as pooled serum, 5 per cent bovine albumin, glycine solution, or polyvinyl pyrrolidone $(30)$, and by the use of the Coombs antiglobulin technique $(26,40)$. None of the modifications appears to have improved the test, and the consensus is that it is not sufficiently specific and reliable to have practical clinical applications in the diagnosis and prognosis of tuberculosis. Nevertheless, the occurrence of high titres in a higher

1 Assisted with funds allocated by the Province of Ontario under the National Health Grants programme of the Department of National Health and Welfare, Ottawa. percentage of tuberculous than non-tuberculous patients is too significant to be ignored.

Few studies have been made in children other than those of Anderson and Platou (41) and those included in their series by Fleming, Runyon, and Cummings (9), and others $(11,18)$. Anderson and Platou, while recognizing limitations in the test, tended to regard it favourably as to its clinical usefulness in children.

Most workers have noted the occurrence of positive reactions in individuals not believed to have had tuberculosis as well as of negative reactions in patients with tuberculosis. The reasons for these false reactions have not been clarified. It is difficult to rule out past subclinical tuberculous infection as a reason for false positives especially in adults. In this respect, further studies in children of different age groups from areas with a low incidence of tuberculosis should be of interest.

Our experience with the hemagglutination test, recorded here, includes studies in infants, children, and adults as well as in a series of experimental animals.

\section{METHODS}

The technique of the hemagglutination test was that described by Middlebrook (24) with few modifications. Sera were inactivated at $65^{\circ} \mathrm{C}$. for 3 minutes instead of $56^{\circ} \mathrm{C}$. for 30 minutes and were diluted before use with 2 volumes of phosphate-buffered saline instead of 3 volumes. Heterophile antibodies were found to be removed more readily by absorbing each serum three times with unsensitized sheep erythrocytes. The mixture of serum with unsensitized cells was shaken for 20 minutes at room temperature, centrifuged, and the supernatant removed to fresh cells for reabsorption. Serial dilutions of the final supernatant were made in $0.4 \mathrm{ml}$. volumes to which were added equal volumes of a 0.5 per cent suspension of sensitized sheep cells. Standard concentrated old tuberculin, lot 27-1, prepared by the Connaught Medical Research Laboratories was used to sensitize the erythrocytes instead of the Lederle $4 \mathrm{X}$ tuberculin. These two tuberculins were compared by Armstrong and Orlicki 
(42) and found to be equally sensitive and specific in the performance of this test. Freshly sensitized sheep erythrocytes were prepared for each daily series of tests (43).

The standard controls included tubes to show inagglutinability of the sensitized cells in phosphate-buffered saline, complete absorption of heterophile antibodies using unsensitized cells, and proper cell sensitization using a standard serum with a titre of 1:1024 prepared by immunizing rabbits with B.C.G.

Titres of less than 1:4 were recorded as negative. Those of $1: 4$ and $1: 8$ were classified with the negatives as insignificant, and those of $1: 16$ or over were considered positive.

\section{RESULTS}

\section{In children}

Figure 1 shows the hemagglutinin titres found in 165 children.

Sera from 15 newborn infants with erythroblastosis fetalis all gave completely negative reactions.

The other 150 children comprise three groups. The first 50 were under 5 years of age, the second 50 were between the ages of 5 and 14 years. Most of these 100 children were ill with mild upper respiratory infections or various other diseases, but none had evidence of recent or past tuberculosis, and all had negative Mantoux reactions. The third group of 50 children were under 5 years of age, and all had active tuberculosis which was proven by positive cultures and/or guinea pig inoculations in 31 . The disease was clinically typical in the remaining 19 . The manifestations of tuberculosis were primarily pul-

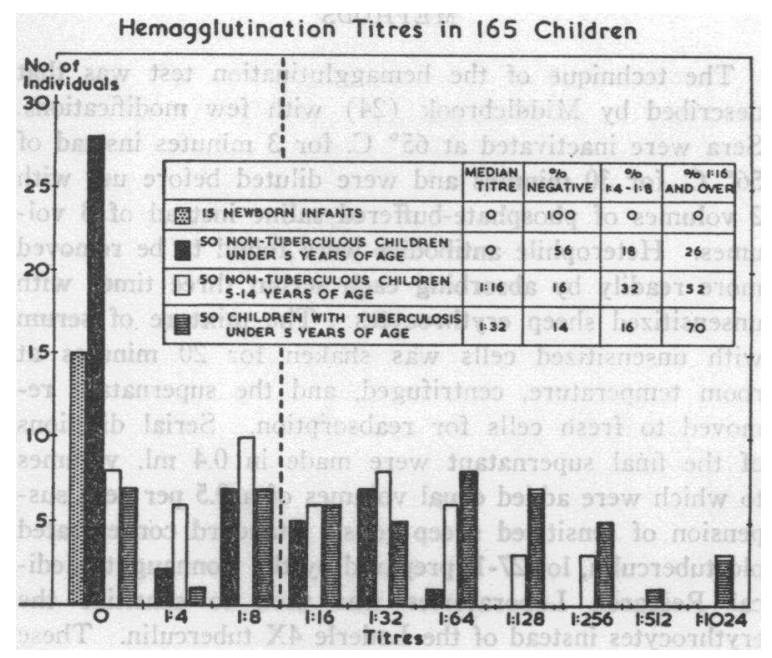

FIGURE 1 monary in 40 , while 10 were cases of tuberculous meningitis with pulmonary lesions.

In the younger control group the hemagglutinin titre was negative in 28 ( 56 per cent) and a further 9 showed titres of only $1: 4$ and $1: 8$, a 74 per cent incidence of insignificant reactions. There were fewer negatives, 16 per cent, in the older control group, and only 48 per cent altogether with insignificant titres. Both groups, therefore, showed false positive reactions; 26 per cent in the younger and 52 per cent in the older children, a significant difference between the two groups. There were differences as well in the range of titres. The highest found in the younger children was $1: 64$ (one patient), while in the older group there were 12 at or above this level and up to $1: 256$.

The reasons for these false positives or for the rising incidence with increasing age are obscure. False positives have been attributed to tuberculin testing. According to Smith and Scott (8), and others, tuberculin testing will stimulate the formation of hemagglutinins, but Colwell and Pitner (23) and Anderson and Platou (41) found that this would not occur readily in non-reactors to tuberculin. Unfortunately all sera could not be collected before Mantoux testing. However, tuberculin testing and serum collection was done similarly in both groups. Moreover, many sera were collected on the same day as the Mantoux test and most within 48 hours of it. Of the 13 false positives in the younger group, 9 were collected before or on the same day as the Mantoux test was done, and all but 2 within 48 hours. Of the 26 false positives in the older group, 13 were taken before or on the same day and another 8 within 48 hours. The six highest titres of $1: 128$ and 1:256 included two sera collected on the same day, two in 24 hours, one in 48 hours and one in 72 hours after the Mantoux test was done. It is difficult to believe that antibodies in such titres would appear so soon after a single antigenic stimulus. Moreover, antibodies would not be expected so early in a group of tuberculin positive individuals where a "booster dose" effect might be anticipated. In our opinion, Mantoux testing has not affected the results.

In the last group of 50 children, those under five years of age with proven tuberculosis, 70 per cent showed positive titres ranging from 1:16 up to 
$1: 1024$. This is significantly different from the control group of similar age (26 per cent) and from the older control group (52 per cent) though the latter difference is less marked. The median titre was $1: 32$ in the tuberculous group, but was $1: 16$ in the older non-tuberculous children and less than $1: 4$ in the non-tuberculous groups under five years of age. In the tuberculous group, however, 30 per cent had insignificant titres; 7 or 14 per cent were negative. These false negatives could not be correlated with the extent or type of tuberculosis, nor with the use, early or otherwise, of antibiotic therapy. Of the ten cases with proven tuberculous meningitis which are included in this group, four gave false negative reactions; this finding is in disagreement with the suggestion of Nommik and Meakins (43) that high titres are seen in an unusually high percentage of cases with tuberculous meningitis.

\section{In adults}

Figure 2 shows the hemagglutinin titres in 200 adults comprising four groups.

There are 50 healthy young adults, blood donors from the hospital transfusion service, without clinical evidence of tuberculosis. A tuberculin test was not done. Insignificant titres were found in 62 per cent of these of which six, or 12 per cent, were negative. However, 38 per cent showed titres ranging from $1: 16$ to $1: 256$. The median for the entire group was $1: 8$. The pattern as regards false positives was very similar to that in the control group of older children, and the reason for it is equally obscure. It is more difficult in these adults to disregard the possibility of previous exposure to the tubercle bacillus.

The second group comprises 50 adults with presumably early tuberculosis. These sera were collected at or shortly after the time when tuberculous disease was first diagnosed. The tuberculosis was not of the chronic fibro-caseous type, and the histories were largely of short duration. There was a sharp contrast with all normal groups. All showed hemagglutinins, with 96 per cent in the significant range of $1: 16$ to $1: 1024$. There were only two (4 per cent) with insignificant titres. This group differs significantly as well from the cases of tuberculosis in young children.

Almost exactly similar to this group is the third comprising 50 adults with chronic fibro-caseous pulmonary tuberculosis. Hemagglutinins ranging in titre from $1: 16$ to $1: 1024$ were found in 94 per cent. Again none were negative, but three or 6 per cent gave insignificant titres of $1: 8$.

Finally there are 50 adults, treated cases of tuberculosis, whose tuberculosis had been considered arrested or "cured" for from one to sixteen years. These sera were collected at a clinic where such patients are examined periodically for evidence of reactivation. Only one serum was completely negative, and 22 per cent showed insignificant results. The range of titres in the 78 per cent with significant hemagglutinins was somewhat lower than in the active cases, ranging up to $1: 512$ only, with a median for the group of $1: 32$.

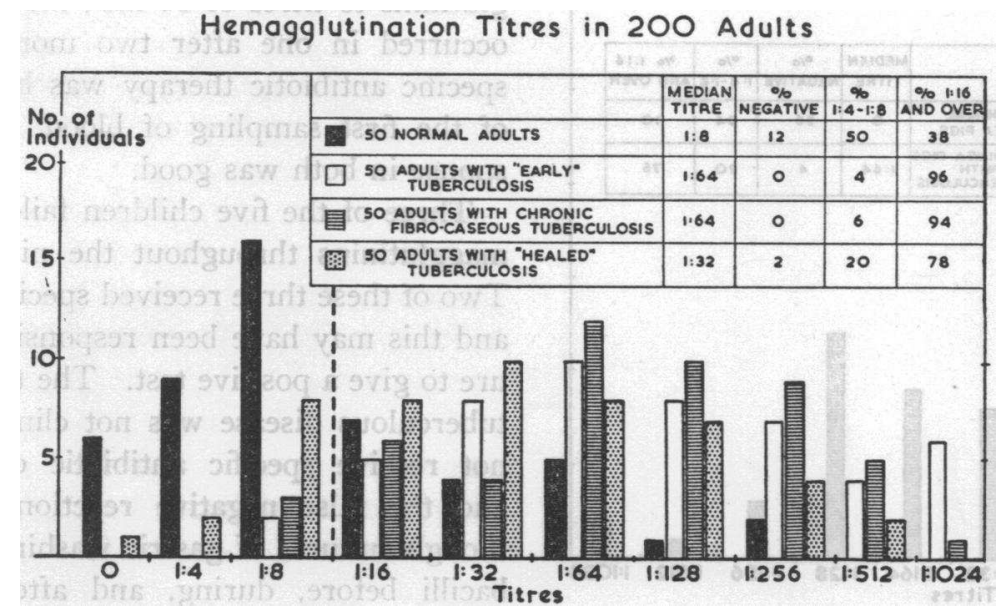

FIGURe 2 
The median titre for the previous two groups with active tuberculosis was $1: 64$. These findings differ significantly both from those seen in all non-tuberculous controls and in adults with active tuberculosis, but are somewhat similar to the results in young children with tuberculosis. The small percentage of arrested cases of tuberculosis with insignificant hemagglutinin titres makes it doubtful that the test is of value as a guide to the activity of the tuberculous process.

\section{In animals}

Figure 3 shows the hemagglutinin titres in 50 unselected guinea pigs with proven tuberculosis induced by the subcutaneous injection of exudates from tuberculous patients. The sera were collected immediately preceding autopsy of the animals at two months. These titres are compared with those of 50 unselected uninoculated guinea pigs. Hemagglutinins were present in 22 of the controls, and 5 had titres of $1: 16$. Two of the tuberculous animals failed to show agglutinins, 10 had titres below $1: 16$, and 38 had titres varying from $1: 16$ to $1: 1024$. There was no correlation between titre and extent of tuberculosis, though one of the negative pigs had extensive disease. The difference between the two groups is highly significant. Nevertheless it would seem that in dealing with guinea pigs one might expect false positive reactions in 10 per cent of un-

\section{Hemagglutination Titres in 100 Guinea Pigs}

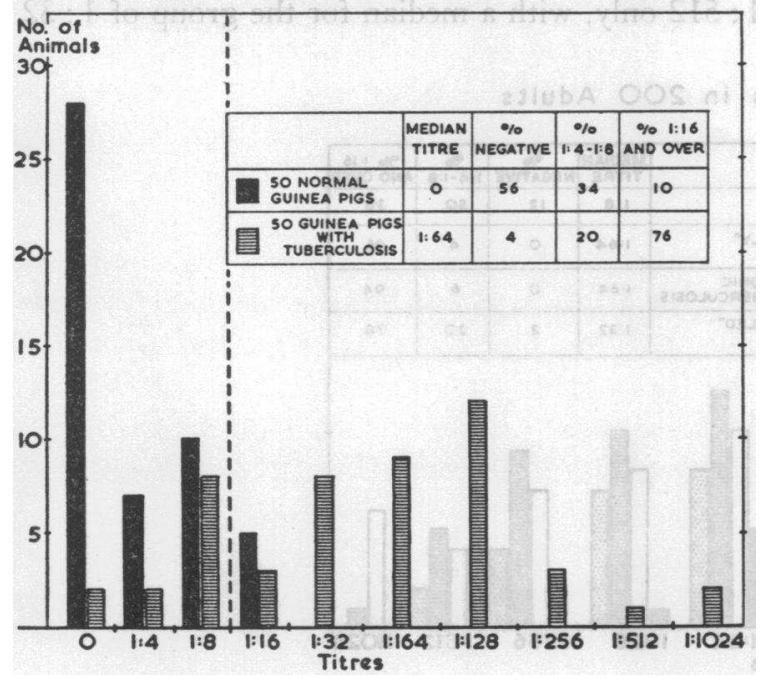

Figure 3

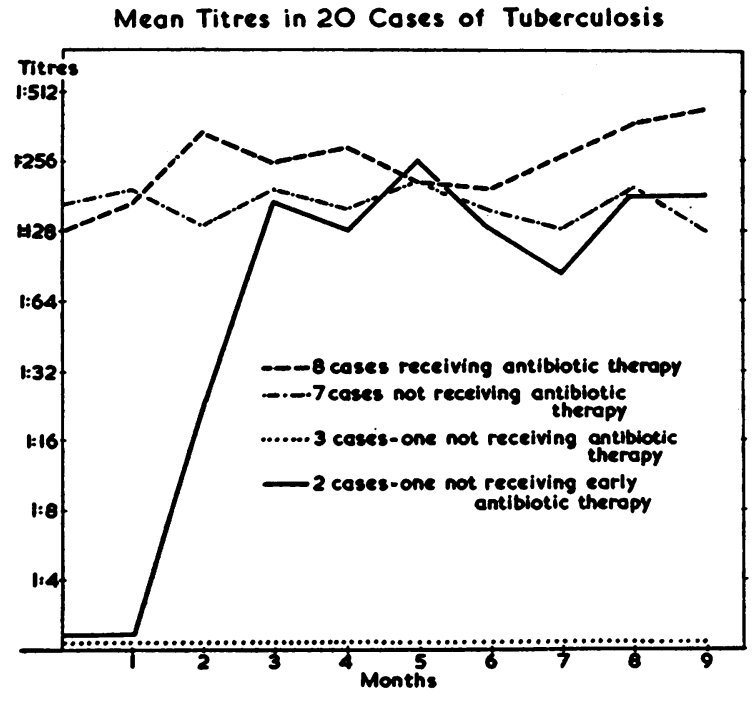

Figure 4

infected animals and false negative reactions in 24 per cent of tuberculous ones.

\section{Miscellaneous observations in children and animals}

Twenty selected children with active tuberculosis (pulmonary and meningeal) were followed by monthly hemagglutinin titrations for nine months. Figure 4 shows the means of the titres set out in four groups.

Five children gave negative hemagglutination reactions when first tested. These false negative reactions may have been found because the initial samples of sera were taken too early in the course of the disease.

Two of the five subsequently developed hemagglutinins to titres of $1: 128$; the positive response occurred in one after two months even though specific antibiotic therapy was begun at the time of the first sampling of blood. The clinical response in both was good.

Three of the five children failed to develop hemagglutinins throughout the nine-month period. Two of these three received specific chemotherapy, and this may have been responsible for their failure to give a positive test. The third child, whose tuberculous disease was not clinically severe, did not receive specific antibiotic or chemotherapy, and the false negative reactions persisted even though cultures of gastric washings grew tubercle bacilli before, during, and after the period of observation. 
Fifteen of the children had hemagglutinins initially. Eight of the 15 received specific antibiotic and chemotherapy, seven did not. The titres of most individuals remained at a fairly constant level during the nine-month period. The mean titres of the two groups (shown in Figure 4) were maintained at a fairly constant and similar level throughout. There were no detectable differences between those receiving and those not receiving antibiotic and chemotherapy and no correlation with clinical response to therapy.

The Coombs antiglobulin technique was used in 45 selected children following the suggestion of Meynell (40). This technique was investigated to find out if positive reactions in tuberculous cases could be differentiated from false positive reactions in non-tuberculous patients by demonstrating significantly higher titres of "incomplete" antibodies in the sera of patients with tuberculosis. It was also used to determine if "incomplete" antibodies could be detected in the sera of patients with tuberculosis giving false negative hemagglutination reactions.

The red blood cells in the tubes failing to show agglutination were washed thoroughly with buffered saline and mixed with a rabbit anti-humanglobulin serum found satisfactory for $\mathrm{Rh}$ work. This serum failed to agglutinate control unsensitized or tuberculin sensitized sheep cells.

The procedure increased the titres of some sera, but not all. Increases could be demonstrated in only 28 of the 45 cases; the increase was usually 2 -fold to 8 -fold and rarely 128 -fold. Such increases tended to occur more frequently in sera from tuberculous cases than from controls, but this was inconstant. Of particular interest were the five tuberculous cases referred to earlier with negative initial hemagglutinin tests. Only three of the five were positive by the Coombs method; the titre in one was $1: 16$ and in two it was $1: 128$. All five cases were investigated serologically for nine months. One child receiving chemotherapy remained negative throughout to both tests. Two children remained negative throughout by the usual hemagglutinin test but showed titres of $1: 128$ for nine months by the Coombs technique. The remaining two patients developed hemagglutinins subsequent to the first examination. In one of these two the Coombs test always showed titres from two to eight times the titre of the he- magglutination test, but in the second child the Coombs test never showed a titre higher than the hemagglutinin titre.

Tuberculin testing was discussed earlier as a possible reason for false positive reactions in nontuberculous children. Tests were done in guinea pigs to determine how readily a hemagglutinin response might occur following the injection of tuberculin. Nine guinea pigs with negative hemagglutination tests were given repeated subcutaneous injections of $50.0 \mathrm{mg}$. of old tuberculin at two-week intervals for 16 weeks. This dose is 1000 times the quantity used for routine Mantoux testing in our Hospital. At 2 weeks, four animals were negative, three had titres of $1: 4$, and two had titres of $1: 16$. At 4 weeks, four of the nine guinea pigs remained negative, three had titres below 1:16, and the titres of two had increased to $1: 64$. Not until the end of 8 weeks (four injections) were positive tests obtained in all animals; the highest titre was $1: 64$, and five had titres of only $1: 4$ or $1: 8$. The titres were much the same at 14 and 16 weeks. The hemagglutinin response to tuberculin injections in guinea pigs thus is slow and poor.

An attempt was made to determine if antigens other than those derived directly from the tubercle bacillus could stimulate the formation of antibodies which would agglutinate tuberculin sensitized erythrocytes. Groups of young guinea pigs with initially negative hemagglutination tests were given three subcutaneous injections at two-week intervals of various antigens, and blood samples were collected two weeks after the last injection. Thirteen pigs were given a mixed formalin killed vaccine made from freshly isolated nasopharyngeal strains of Staphylococcus pyogenes, Diplococcus pneumoniae, Streptococcus pyogenes (Lancefield Group A.), Hemophilus influenzae (Type b.), Streptococcus sp. (viridans), Neisseria sp., and diphtheroids. All remained negative to the hemagglutination test but one which had a titre of $1: 8$. Eight guinea pigs received injections of fluid diphtheria toxoid. Four developed titres of $1: 32$, two had titres of $1: 16$, and only two remained negative to the test. Seven guinea pigs were given a vaccine prepared from a saprophytic orange-pigmented mycobacterium which has been grown on several occasions from gastric washings from infants and children. All became 
positive to the hemagglutination test with the titres ranging from $1: 32$ to $1: 256$. Two were at a titre of $1: 256$, three at $1: 128$, one at $1: 64$, and one at $1: 32$.

\section{DISCUSSION}

There are obvious and significant differences in the incidences of positive hemagglutination tests at a titre of $1: 16$ or more between the tuberculous and non-tuberculous cases in any age group. These differences are also apparent in the ranges of titres.

While this is true, the test has little or no practical diagnostic value, except perhaps in those few cases of tuberculosis with exceptionally high titres, because of the occurrence of so many false negative reactions in the tuberculous group and false positive reactions in the non-tuberculous group. False reactions in both directions were obtained as well in control and tuberculous guinea pigs. The arbitrary dividing point chosen between nonsignificant and significant titres, levels of $1: 8$ to $1: 16$, seemed to fit best the group as a whole, though a $1: 4$ to $1: 8$ division would have produced better differentiation in adults as regards insignificant reactions in active cases. The addition of a Coombs technique did not make the test more specific, though it is of interest that a few, but not all, tuberculous cases with negative hemagglutination tests gave moderately high titres by this added procedure.

The hemagglutination test lacks practical prognostic significance as an index of the activity of the tuberculous process, even though there was a somewhat significant difference in the incidence of negative or insignificant titres between those adults with early or chronic active tuberculosis and those considered clinically as "cures." The pattern of the titres in "healed" adult tuberculosis differed little from that in active tuberculosis in children under five years of age. Children with active tuberculosis who received clinically effective specific antibiotic and chemotherapy for nine months failed to show a tendency to have lower titres. This period of observation may have been too short.

The reasons for false negative results in proven cases of tuberculosis are obscure. False negatives were of significantly greater frequency in early childhood tuberculosis than in adult cases. From our series, this could not be attributed to early specific antibacterial therapy or to massive infec- tion. It would appear that antibody response is poor in certain individuals, and this occurs more frequently in early childhood.

Of great interest are the false positive reactions obtained in non-tuberculous humans as well as in non-tuberculous animals, and of particular interest are the frequencies of such reactions in different age groups. The incidence of false positive tests rose from 0 per cent in newborn infants to 26 per cent in children under five years of age and to 52 per cent in children of five years or over while the incidence of completely negative tests fell in the three groups from 100 per cent to 56 per cent to 16 per cent, respectively. The adult controls differed little from the group of older children. These positives cannot be explained by tuberculin testing in the control children. It is difficult to rule out past sub-clinical tuberculous infection in adults. This factor, in our opinion, may be discounted in the young children. The probability of exposure at their age and in a community with a relatively low incidence of tuberculosis is minimal. Furthermore, clinical evidence of tuberculosis was absent, and Mantoux tests were negative.

Whether the increasing incidence of false positive tests from infancy to age 14 is an expression of some "maturation factor" of a completely non-specific nature is not known. Our findings, including the better antibody response in tuberculous adults, suggest a "secondary" or "booster" effect of an antigen to which individuals have been exposed on one or more occasions. The test appears to have a high degree of specificity in cases of tuberculosis. But in the non-tuberculous controls especially in children, the findings suggest an immunological stimulation by an antigen or antigens having some common factor with the tubercle bacillus. In this respect, the demonstration that antibodies capable of agglutinating tuberculin sensitized erythrocytes could be produced in guinea pigs by antigenic substances not prepared from the tubercle bacillus, such as fluid diphtheria toxoid and a suspension of a saphrophytic mycobacterium, is of interest. Antigenic exposure to diphtheria toxoid is common in childhood. Exposure under natural conditions to this particular mycobacterium to a degree which would result in the formation of hemagglutinins cannot be disregarded as a possible explanation of false positive hemagglutination tests. This could occur during the course of upper respiratory infections caused 
by other micro-organisms, or for other reasons, and the chance of such antigenic exposure might increase with age. Factors such as these could account for the increasing incidence with age of false positive hemagglutination tests and the better antibody response seen in adults with tuberculosis.

If this thesis proves valid, namely, that the defects of the test are due to antigens shared by the tubercle bacillus (or present in tuberculin) and common substances to which individuals may be exposed, there is little hope for clinical usefulness of the test until antigens specific for pathogenic strains of $M$. tuberculosis are found which are capable of sensitizing erythrocytes.

\section{SUM MARY}

1. The Middlebrook-Dubos hemagglutination test, using tuberculin sensitized erythrocytes, has been studied in children, in adults, and in a series of experimental animals.

2. A hemagglutinin titre of $1: 16$ or more was found in only 70 per cent of children under five years of age with active tuberculosis and in 95 per cent of adults with active tuberculosis. The incidence of false negative reactions decreased with age.

3. A hemagglutinin titre of $1: 16$ or more was found in 0 per cent of newborn infants, in 26 per cent of non-tuberculous children under five years of age, in 52 per cent of non-tuberculous children 5 to 14 years of age, and in 38 per cent of normal adults. The incidence of false positive reactions increased with age.

4. False positive and false negative reactions were also found to occur in experimental animals.

5. The test had very limited value in the laboratory diagnosis of tuberculosis because of the frequency of false positive reactions in non-tuberculous individuals and of false negative reactions in active cases of tuberculosis especially in children.

6. A Coombs modification of the hemagglutination test did not make the results more specific.

7. The hemagglutination test failed to differentiate accurately between active cases of tuberculosis and "healed" cases or to detect clinical regression of the disease during nine months of specific antibiotic and chemotherapy.

8. An antibody capable of agglutinating tuberculin sensitized sheep erythrocytes was found to develop in all of seven guinea pigs injected with a saprophytic mycobacterium, in six of eight guinea pigs injected with diphtheria toxoid, and in one of thirteen guinea pigs injected with a vaccine of mixed nasopharyngeal bacteria.

\section{ACKNOWLEDGMENTS}

14

The authors are grateful to Professor P. H. Greey and to Dr. A. R. Armstrong, Director of Laboratories, The Mountain Sanatorium, Hamilton for most helpful advice; to Dr. H. T. McClintock, Director of the Chest Clinic, The Gage Institute, Toronto, for providing the sera from adults with arrested tuberculosis and to Dr. A. G. S. Heathcote, Director of Laboratories, The Toronto Hospital for Tuberculosis for sera from adults with active tuberculosis.

\section{REFERENCES}

1. Middlebrook, G., and Dubos, R. J., Specific serum agglutination of erythrocytes sensitized with extracts of tubercle bacilli. J. Exper. Med., 1948, $88,521$.

2. Middlebrook, G., and Dubos, R. J., Serologic reaction in tuberculosis. Am. Rev. Tuberc., 1948, 58, 700.

3. Rothbard, S., Dooneief, A. S., and Hite, K. E., Practical application of a hemagglutination reaction in tuberculosis. Proc. Soc. Exper. Biol. \& Med., 1950, 74, 72.

4. Rothbard, S., A serologic test in tuberculosis. Med. Clin. N. Am., 1951, 35, 603 (Nationwide number).

5. Scott, N. B., and Smith, D. T., A simple modification of the Middlebrook and Dubos hemagglutination test for serum antibodies to products of tubercle bacilli. J. Lab. \& Clin. Med., 1950, 35, 303.

6. Sohier, R., Réaction d'Hémagglutination, Type Dubos Middlebrook Réalisée avec une Tuberculin purifiée. Résultats Obtenus. Ann. Inst. Pasteur, 1950, 78, 283.

7. Gernez-Rieux, Ch., and Tacquet, A., La Réaction d'Hémagglutination dans la Tuberculose. Ann. Inst. Pasteur de Lille, 1950, 3, 1.

8. Smith, D. T., and Scott, N. B., Clinical interpretation of the Middlebrook-Dubos hemagglutination test. Am. Rev. Tuberc., 1950, 62, 121.

9. Fleming, J. W., Runyon, E. H., and Cummings, M. M., An evaluation of the hemagglutination test for tuberculosis. Am. J. Med., 1951, 10, 704.

10. Kirby, W. M. M., Burnell, J. M., and O'Leary, B., Evaluation of the hemagglutination reaction in the diagnosis of active tuberculosis. Am. Rev. Tuberc., 1951, 64, 71.

11. Young, R. M., and Leonard, W. A., Jr., Clinical evaluation of the Middlebrook-Dubos hemagglutination test. Am. J. Clin. Path., 1951, 21, 1045.

12. Spain, D. M., Childress, W. G., and Rowe, C., The hemagglutination test in tuberculosis. Am. J. Clin. Path., 1952, 22, 86. 
13. Cuthbert, R. J., Serological reactions in tuberculosis: with particular reference to the haemagglutination test. Glasgow M. J., 1952, 33, 107.

14. Hentel, W., and Guilbert, G. D., Results in the hemagglutination test for tuberculosis. J. Lab. \& Clin. Med., 1952, 39, 426.

15. Bunn, P., Drobeck, B., Gino, J., and Adair, C., Some observations upon the Middlebrook-Dubos hemagglutination test in man and animals. Ann. Int. Med., 1952, 37, 84.

16. Hollander, A. G., Frobisher, M., Jr., and Kalisch, K., Clinical evaluation of the hemagglutination reaction. Am. Rev. Tuberc., 1953, 67, 497.

17. Sievers, O., Ulstrup, J., and Winblad, S., Serumreaktion med fårblodkroppar sensibiliserade med polysacharidextrakt av tuberkelbakterier. Nord. med., 1950, 43, 667.

18. Sohier, R., Trimberger, I., and Juillard, J., Réaction d'Hémagglutination type Middlebrook-Dubos Réalizée avec les Hématies humaines $O$ et la Nouvelle Tuberculine I.P. 48. Ann. Inst. Pasteur, 1950, 79, 347.

19. Adcock, J., Haley, R. R., and Davey, W. N., The Middlebrook hemagglutination test for tuberculosis : an evaluation in normal subjects and in patients with tuberculosis. J. Lab. \& Clin. Med., 1951, 38, 736.

20. Hilson, G. R. F., and Elek, S. D., The haemagglutination reaction in tuberculosis. J. Clin. Path., 1951, 4, 158.

21. Hinson, K. F. W., Jones, A. R., and Chamberlin, J. A., The Middlebrook-Dubos reaction in relation to the clinical aspects of pulmonary tuberculosis. Brit. J. Tuberc., 1952, 46, 50.

22. Yaoi, H., Takei, M., and Maeda, H., Practical application of specific hemagglutination with sera from tuberculous patients and sensitized fowl erythrocytes. Yokohama Med. Bull., 1951, 2, 1.

23. Colwell, C., and Pitner, G., Agglutination of sensitized sheep erythrocytes and collodion particles by tuberculous and normal sera. J. Clin. Invest., 1952, 31, 238.

24. Middlebrook, G., A hemolytic modification of the hemagglutination test for antibodies against tubercle bacillus antigens. J. Clin. Invest., 1950, 29, 1480.

25. Gernez-Rieux, Ch., and Tacquet, A., Le Phenomène de l'Hémolyse Conditionnée dans la Tuberculose. Ann. Inst. Pasteur, 1951, 81, 149.

26. Hall, W. H., and Manion, R. E., Hemagglutinins and hemolysins for erythrocytes sensitized with tuberculin in pulmonary tuberculosis. J. Clin. Invest., 1951, 30, 1542.

27. Maillard, E. R., and Gagliardo, F. J., A new serologic test for tuberculosis. Preliminary Report. Am. Rev. Tuberc., 1951, 64, 675.

28. Mollov, M., and Kott, T. J., A comparative study of the hemagglutination test for antibodies and its hemolytic modification in tuberculosis. Am. Rev. Tuberc., 1952, 65, 194.
29. Lucentini, L., and Boisvert, H., Contribution à l'Etude des Réactions d'Hémagglutination et d'Hémolyse Conditionnée dans la Tuberculose. Ann. Inst. Pasteur, 1952, 82, 55.

30. Gerst1, B., Kirsh, D., Andros, E. M., Winter, J. W., and Kidder, L. E., Evaluation of hemolytic modification of Middlebrook-Dubos test for tuberculous antibodies. Am. J. Clin. Path., 1952, 22, 337.

31. Schwartz, B., Mandelbaum, T., Spitz, L. J., Schmidt, P. P., and Battaglia, B., A comparative evaluation of the hemagglutination test and the hemolytic modification in tuberculosis. Am. Rev. Tuberc., 1952, 66, 594.

32. Rowe, C., Spain, D. M., and Childress, W. G., An evaluation of the complement-fixation modification (Maillard) of the hemagglutination test in tuberculosis. Am. Rev. Tuberc., 1952, 66, 621.

33. Sherris, J. C., The Middlebrook-Dubos haemagglutination test and its haemolytic modification in the diagnosis of tuberculosis. J. Clin. Path., 1953, 6, 64.

34. Thalhimer, W., and Rowe, C., A slide test modification of the hemagglutination test for antibodies against tubercle bacilli. Am. Rev. Tuberc., 1951, 63, 667.

35. Gernez-Rieux, Ch., and Tacquet, A., Réactions d'Hémagglutination Pratiquées Comparativement avec l'Antigène Type Middlebrook et Dubos et avec la Tuberculine Précipitée. Ann. Inst. Pasteur, 1950, 78, 550.

36. Pound, A. W., Observations on the agglutination and haemolysis of red cells treated with extracts of Mycobacterium tuberculosis: An evaluation of methods. J. Path. \& Bact., 1952, 64, 131.

37. Boyden, S. V., The adsorption of proteins on erythrocytes treated with tannic acid and subsequent hemagglutination by antiprotein sera. J. Exper. Med., 1951, 93, 107.

38. Maillard, E. R., Further studies of a new serologic test in tuberculosis. Am. J. Pub. Health, 1952, 42, 175.

39. Marois, P., and Borduas, A. G., Analyse des Antisérums Tuberculeux Expérimentaux par l'Emploi de Deux Techniques d'Hémagglutination Passive. Canad. J. Pub. Health, 1953, 44, 28.

40. Meynell, G. G., A sensitive modification of the Middlebrook-Dubos haemagglutination test. J. Path. \& Bact., 1952, 64, 647.

41. Anderson, H. W., and Platou, R. V., MiddlebrookDubos hemagglutination reaction: Study of the test in children. Pediatrics, 1951, 8, 498.

42. Armstrong, A. R., and Orlicki, J., The technique of the sensitized sheep cell haemagglutination test for tuberculosis. Canad. J. Med. Tech., 1951, 13, 67.

43. Nommik, S., and Meakins, J. F., The MiddlebrookDubos haemagglutination reaction in the diagnosis and progress of tuberculosis. Canad. M. A. J., $1953,69,140$. 